\title{
Local air quality management process in Great Britain in its second round of review and assessment: efficiency vs. effectiveness
}

\author{
S. M. Hassan, K. A. Ling \& J. W. S. Longhurst \\ Air Quality Management Resource Centre, Faculty of Applied Sciences, \\ University of the West of England, Bristol, UK
}

\begin{abstract}
Local authorities across Great Britain are required under the Environment Act 1995 to review and assess air quality in their areas. Accordingly, local authorities have undertaken two rounds of review and assessment since 1997. In 2003, the Government and the Devolved Administrations introduced a new prescriptive approach to Local Air Quality Management (LAQM) in which they direct local authorities to consider specific air pollution sources and issues in a more standardised manner. This paper presents results from a project which evaluated the second round of LAQM in the context of increased prescription and explores the capabilities of local authorities to deliver better air quality. Results indicate that local authorities identified a number of new air pollution hotspots during the second round of LAQM. These areas were not identified in the first round of LAQM, which suggests that the enhanced prescription of guidance has led to their identification. Also, it was evident that increased technical and managerial capabilities of local authorities and the experience gained from conducting the first round of LAQM have contributed to the identification of new pollution hotspots. These results indicate that the LAQM in Great Britain is identifying pollution problems efficiently. However, there are uncertainties regarding its effectiveness in terms of delivering better air quality.

Keywords: Local Air Quality Management (LAQM), Air Quality Review and Assessment, Detailed Assessment (DA), Updating and Screening Assessment (USA), Air Quality Management Areas (AQMAs), Air Quality Action Planning (AQAP), Air Quality Objective (AQO).
\end{abstract}




\section{Background}

The statutory basis of air quality management in Great Britain is provided by the Environment Act 1995 [1]. The Act charges local authorities with working towards achieving air quality objectives by means of a Local Air Quality Management (LAQM) process. The Air Quality Objectives (AQOs) apply in areas where the public may be exposed for the averaging time of the relevant objective. Local authorities are required to identify areas in which air quality objectives will be exceeded by a target date and to declare these areas as Air Quality Management Areas (AQMAs). In such areas a local authority must develop an Air Quality Action Plan (AQAP) detailing the measures to be taken and the timescale for implementation in order to achieve the air quality objectives within the AQMA.

The key element in the LAQM regime, according to the Environment Act 1995, is a 'review and assessment' of air quality in the local authority's area of jurisdiction. The Government and the Devolved Administrations (Scottish Executive and Welsh Assembly Government) have issued a series of guidance documents, supported by training sessions and telephone and e-mail helpdesks, to assist local authorities in carrying out their reviews and assessments. Local authorities began the process of review and assessment in 1998 and the first round of the process was concluded in 2001. In this first round, the local authorities exercised substantial latitude to make their own interpretations about the policy and technical aspects of their review and assessment. One conclusion of the first round, the process was subject to a comprehensive evaluation drawing upon a wide range of stakeholder views [2]. A substantial number of changes were proposed leading to new review and assessment approach for the second round. Subsequently, the Government and the Devolved Administrations issued new guidance documents in March 2003 [3,4] to assist local authorities in carrying out the second round of review and assessment (2003-2004) which comprises two steps. The first is an Updating and Screening Assessment (USA) in which each local authority has to identify changes to circumstances since the first round and complete a risk assessment to identify areas where air quality objectives are likely to be exceeded. Where a risk is identified, the local authority must proceed to the second step, a Detailed Assessment (DA).

This paper presents some results obtained from a three years research project, the main aim of which was to evaluate the second round of air quality review and assessment in the context of increased prescription in the process. This evaluation involved an examination of the outcomes of this round of review and assessment. Also, it involved an assessment of some technical and managerial aspects of the air quality management practices of local authorities across Great Britain in the second round of review and assessment.

\section{Methodology}

A combination of three research methods was adopted: questionnaire surveys to British local authorities, secondary analysis of data extracted from local 
authorities' air quality review and assessment reports, and case study interviews in five British local authorities.

The first questionnaire survey was sent to environmental health professionals in all the 407 British local authorities during the USA stage of the review and assessment process. 175 responses were received from this questionnaire $(43 \%)$. The second questionnaire was sent to all 202 British local authorities that progressed to DA. 107 responses were received from this questionnaire $(53 \%)$.

Regarding the secondary data analysis, the first set of analyses was carried out using USA reports of 388 British local authorities. The second set of analysis used reports from 155 local authorities.

Finally, environmental health professionals from 5 British local authorities were selected for face-to-face case study interviews. These authorities were: Reigate and Banstead Borough Council (BC), Slough BC, Oldham Metropolitan Borough Council (MBC), Gloucester City Council (CC) and Glasgow CC.

\section{Results and discussion}

\subsection{Outcomes of the review and assessment}

Results of the secondary data analysis show that during Round 2 of air quality review and assessment, about half of the 407 British local authorities progressed to a DA. Of those authorities that progressed to DA, 57\% declared new AQMAs. These results suggest that new AQO exceedences have been identified during Round 2 of review and assessment.

Results from the questionnaire survey indicate that $61 \%$ of the 175 respondents thought that the main reason that prompted the DAs was new air pollution monitoring and/or modelling results in hotspot locations suggested by the new Technical Guidance [4]. Such hotspot locations include busy roads, road junctions and street canyons. These results were later clarified by the case study interviews. All 5 interviewees suggested that the Technical Guidance drew their attention to focus their modelling work in hotspot locations. The new Technical Guidance recommended examination of hotspots locations rather than taking an unfocussed look at a large geographical area. This guided approach focused monitoring and modelling activity in locations that were not identified in the previous round of review and assessment, this implies that the issue may well have been present in Round 1 but simply not identified. Also, the guidance has provided prescriptive procedures for the selection of appropriate monitoring devices and dispersion models.

Regarding AQO exceedences identified during Round 2 of review and assessment, the secondary data analysis conducted after the USA stage showed that AQOs for 1,3 butadiene, lead and carbon monoxide were at a very low risk of being exceeded. Furthermore, the secondary data analysis conducted after the DA stage showed that none of the local authorities that progressed to DA had declared AQMAs in respect of these pollutants. Moreover, there have been no AQMAs declared from Round 1 of review and assessment in respect of these 
pollutants. This suggests that these objectives are set at a level that is already achieved in Great Britain.

From the questionnaire surveys conducted and the secondary data analysis, it is apparent that nitrogen dioxide $\left(\mathrm{NO}_{2}\right)$ and particulates $\left(\mathrm{PM}_{10}\right)$ are the two pollutants causing the greatest challenges to local authorities. Regarding $\mathrm{NO}_{2}$, there are widespread exceedences of the annual mean objective for 2005 compared to the 1-hour objective. It is expected that meeting the annual mean objective in 2005 and the limit value in 2010 will be considerably more demanding than achieving the 1-hour mean [4]. About $95 \%$ of the 134 AQMAs declared in Round 1 of review and assessment included $\mathrm{NO}_{2}$ annual mean exceedences as a result of road traffic [5] and $34 \%$ included $\mathrm{NO}_{2}$ annual mean exceedences only [6].

Transport has long been recognised as the major contributor to emissions in locations requiring AQMAs [7]. Road transport is the largest source of nitrogen oxide $\left(\mathrm{NO}_{\mathrm{x}}\right)$ emissions in the UK, contributing 49\% of total emissions in 2000 [8]. An analysis of $\mathrm{NO}_{2}$ concentrations during 2001 for 212 automatic monitoring sites showed that the $\mathrm{NO}_{2}$ annual mean concentrations were above $40 \mu \mathrm{g} / \mathrm{m}^{3}$ at most roadside and kerbside sites in London and at about half of background sites. Exceedences outside London were mainly at roadside and kerbside monitoring sites [8].

The significance of traffic growth was highlighted by the case study interviewees in Slough BC and Glasgow CC. In Slough BC, the interviewee anticipated identifying new AQOs exceedences due to traffic sources in the future as concentrations for $\mathrm{NO}_{2}$ in many roadside locations were close to the objectives. Also, the interviewee in Glasgow CC anticipated identifying new AQO exceedences due to traffic growth.

Regarding $\mathrm{PM}_{10}$, the secondary data analysis showed that a considerable percentage $(22 \%)$ of the local authorities that progressed to DA had identified exceedences of a $\mathrm{PM}_{10}$ objective. More than $50 \%$ of the AQMAs declared in Round 1 of review and assessment included exceedences of the 2004 24-hour mean $\mathrm{PM}_{10}$ objective, although the majority of these were in combination with $\mathrm{NO}_{2}$, and were associated with road traffic sources [4].

Few AQOs exceedences for $\mathrm{SO}_{2}$ have been identified during Round 2 of review and assessment. Only a small percentage of the AQMAs declared in Round 1 were solely due to $\mathrm{SO}_{2}(3 \%)$ or include $\mathrm{SO}_{2}$ as a contributor (3\%). A number of potential sources have triggered DAs for $\mathrm{SO}_{2}$ during Round 2 of review and assessment including industrial sources, domestic coal burning, steam railways, and shipping activities in ports. However, after the DA, only 2 local authorities identified $\mathrm{SO}_{2}$ air quality objective exceedences due to industrial sources and 2 other authorities identified exceedences due to railways. These results indicate that the extent of $\mathrm{SO}_{2} \mathrm{AQO}$ exceedence is localised and not as extensive as $\mathrm{NO}_{2}$ and $\mathrm{PM}_{10}$ objective exceedences.

The last pollutant for which AQO exceedence was identified during Round 2 of review and assessment is benzene. None of the local authorities declared AQMAs with respect to benzene during Round 1 of review and assessment. However, this pollutant has triggered a few DAs during this round, $9 \%$ of the 
local authorities that progresses to DA have identified potential AQO exceedences for benzene. Potential sources identified during the USA included industrial sources, oil storage facilities and petrol filling stations. After the DA, only one local authority identified an AQO exceedence of benzene caused by a petrol filling station which is in close proximity to a school. Again, these results suggest that the AQO for benzene is at a very low risk of exceedence despite the new stringent AQOs introduced in 2002.

\subsection{Technical air quality management practices}

Regarding monitoring of air pollutants, the questionnaire survey showed that the majority of local authorities are undertaking some form of air pollution monitoring, especially for pollutants causing the largest number of AQO exceedence (i.e. $\mathrm{NO}_{2}, \mathrm{PM}_{10}$ and $\mathrm{SO}_{2}$ ). For example, it was found that $89 \%$ of the USA questionnaire respondents' authorities are using $\mathrm{NO}_{2}$ diffusion tubes and $67 \%$ of them have $\mathrm{NO}_{2}$ real-time monitors. Furthermore, all the case study authorities were using both diffusion tubes and real-time monitoring devices. Real-time monitors are especially expensive equipment and they require trained operators but they are necessary to assess with confidence air pollution concentrations [4]. The secondary data analysis indicated that $78 \%$ of the local authorities that carried out a DA had used real-time monitors, as they are required to identify with reasonable certainty whether or not a potential AQO exceedence will occur. Besides the existing number of monitoring devices, questionnaire respondents and case study interviewees expressed their intention to increase the number of monitoring devices in future years. These results indicate that a large number of local authorities are investing in air quality monitoring which is suggestive of an advanced technical AQM practice.

The technical capabilities of local authorities in monitoring air pollutants have evolved throughout the years. In a survey conducted in 1994, 55\% of the urban local authorities did not have permanent real-time monitoring equipment [10] and by $2001,91 \%$ of the urban local authorities had real-time monitoring equipment [11].

With respect to modelling of air pollution, results show that the majority of local authorities used some form of air pollution modelling during Round 2 of review and assessment. The most widely used model was the screening spreadsheets of DMRB v1.01. This is a screening tool recommended by the Technical Guidance for use in the USA phase of the review and assessment process as it provides a preliminary indication of air quality near roads based on simple procedure of tables and nomograms. Regarding the use of more advanced models, the results of the DA questionnaire show that these models were used mainly in the DA stage of review and assessment and few authorities have used them in their USA work. It is recommended that modelling should be done at a level comparable with the scale of the problem, i.e. many authorities do not need to undertake complex dispersion modelling, and to do so without clear need will be a drain on time and resources [11].

About $70 \%$ of local authorities that used advanced dispersion models for their DA had employed consultants for this work. Some of the interviewees in the 
case study authorities commented that they tend to employ consultants for advanced modelling work because of the costs involved in purchasing the models, training members of staff, and purchasing some model inputs (e.g. meteorological data). Glasgow $\mathrm{CC}$ was the only case study authority which carried out the DA advanced dispersion modelling work in-house. Also they have purchased their own weather station to generate their own meteorological data. This case study is an example of an advanced air pollution modelling practice where there is evidence of a high degree of investment in modelling of air pollution. However, collaboration in advanced modelling can also be considered evidence of advanced technical and managerial AQM practice. An example of this is the case study authority Oldham MBC, which is a part of the Air Quality Working Group of Greater Manchester and Warrington. This group of local authorities has commissioned the modelling work to a consultant which undertakes their advanced modelling work. Such collaborative effort provides a uniform air pollution modelling approach for all local authorities participating in this group.

\subsection{Managerial air quality practices}

Different departments within a local authority (e.g. transport planning, economic development and land-use planning) need to communicate in order to integrate different policies, which are essential for the successful implementation of AQM. The questionnaire showed that only $21 \%$ of the surveyed local authorities have formal groups to address air quality issues and $18 \%$ of the local authorities discuss air quality issue informally when required. However, the case studies revealed that air quality issues are being addressed during other meetings (e.g. internal transport groups). Only Glasgow $\mathrm{CC}$ has an air quality group specifically established to address air quality issues particularly those related to air quality action planning. . A previous study has identified the communication between local authority departments as deficient, with insularity of departments in evidence [12]. Results from the questionnaire surveys reported in this study have shown that this is still the case in Round 2 of air quality review and assessment.

Case study authorities Slough BC and Glasgow CC emphasised the need for more involvement of economic development functions in the process of AQM. Also, the questionnaire survey showed that the economic development officers were not highly involved in the AQM process in Round 2. This inadequate level of involvement from the economic development functions could be explained by a study that revealed an overall picture of limited attempts by local authorities to integrate economic development and the environment [13]. That study also suggests that policy prescriptions may emphasise the local scale as the relevant level for action, but sustainable development or environmental issues appear to be a relatively unimportant concern for local authority-led economic development policy. However, the introduction of the Local Government Act 2000 [14] has placed a responsibility on local authorities to promote or improve the economic, social and environmental well-being of their area. 
Regarding cooperation between neighbouring authorities in air quality management, the questionnaire survey showed that there was evidence of extensive regional collaboration between authorities. $90 \%$ of the surveyed local authorities were found to be participating in at least one regional group addressing air quality issues. Half of these groups were established before the commencement of the LAQM process (i.e. before Round 1 of air quality review and assessment). Also, all the case study authorities (except Glasgow CC) participate in at least one regional air quality group. The interviewee in Glasgow $\mathrm{CC}$ commented that his council is a big conurbation and it has its own air quality groups. These findings indicate that local authorities have recognised the necessity of tackling air pollution problems on a regional scale even before the introduction of the LAQM regime. Local authorities are choosing to work together even more than before as the LAQM process progresses, particularly if AQMAs are required.

With respect to collaboration between local authorities and external agencies, the questionnaire survey showed that the Environment Agency/Scottish Environment Protection Agency (SEPA) are significantly involved in the regional air quality groups discussed in the previous section. Also, it was found that the Highways Agency and the health authorities were involved in these groups but to a lesser degree compared with Environment Agency/SEPA involvement. However, the case studies demonstrated that there were signs of ineffectiveness in the communication between the local authorities and these agencies. Case study interviewees commented that the communication with these agencies was a one-way process, where they did not get any feedback following the consultation on Round 2 review and assessment reports. These authorities did not identify any AQO exceedences due to industrial sources, hence it is expected that the Environment Agency/SEPA involvement would be less than those authorities with industrial exceedences.

\subsection{LAQM process: efficiency $v$ s. effectiveness}

The results discussed in this paper demonstrated that the LAQM process in Round 2 has become more efficient in terms of identifying the air pollution hotspots. Also, it was evident from this research that the LAQM technical and managerial capabilities of the British local authorities have significantly developed since Round 1. It is apparent that the LAQM process has become more efficient in terms of better understanding of air pollution problems and the experience gained by local authorities regarding managing air quality on a local scale. However, there are uncertainties regarding the effectiveness of the LAQM process in delivering air quality benefits.

The first concern is whether the current LAQM regime has had any impact on pollution concentrations, especially for $\mathrm{NO}_{2}$ and $\mathrm{PM}_{10}$ objectives. Outcomes of this research showed that AQOs of these two pollutants are still widely exceeded across the country. Moreover, the deadlines for meeting the objectives of these two pollutants have already passed (December 2005 and December 2004 respectively). As a result, local authorities will now have to work towards 
bringing $\mathrm{NO}_{2}$ and $\mathrm{PM}_{10}$ concentrations down to the AQOs and then seek further improvement to meet the 2010 objectives.

The second concern is regarding the implementation of Air Quality Action Plans (AQAPs). Results of an evaluation of the air quality action planning through the LAQM process showed that there are several constraints to the action planning process [15]. Engagement of external agencies; assessment of impacts of proposed measures and their associated cost; and lack of funding were identified as the main constraints to implementation of AQAP developed in local authorities across Great Britain.

\section{Conclusion}

Results presented in this paper indicate that British local authorities identified a number of new AQMAs during the second round of LAQM. These areas were not identified in the first round of LAQM, which suggest that the enhanced prescription of guidance have led to their identification. Other factors that contributed to the identification of new AQMAs are the increased technical and managerial capabilities of local authorities and the experience gained from conducting the first round of LAQM. It is apparent from this research that the technical capabilities of local authorities to manage air quality have developed since the first round of review and assessment. However, in some instances more investment in air pollution monitoring and modelling LAQM is required. Results also show that there are signs of good collaborations between local authorities. On the other hand, more collaboration between different departments within local authorities is required.

There are signs that the LAQM process is becoming more efficient. The prescriptive approach to the LAQM process introduced by the Government and the Devolved Administrations in 2003, has improved the robustness of the process of identifying areas of poor air quality. However, there is an uncertainty regarding the effectiveness of the process in achieving the primary aim of the Air Quality Strategy; ensuring that air quality in public places poses no significant risk to health or quality of life. This aim can only be achieved by reducing concentrations of air pollutants in order to attain the AQOs. Accordingly, the LAQM process cannot be considered wholly effective as it identifies poor air quality but fails for remediate it. It is therefore recommended that there needs to be more focus on the implementation of the AQAPs in order to deliver air quality improvements.

\section{Acknowledgements}

The authors would like to thank the Department for Environment, Food and Rural Affairs (Defra), Welsh Assembly Government and the Scottish Executive for allowing access to the national air quality review and assessment archive. Also, they would like to thank all the British local authorities that participated in the questionnaire surveys and the case study interviews. 


\section{References}

[1] HM Government. Environment Act 1995. HMSO: London, 1995.

[2] Laxen, D., Wilson, P., Beattie, C., Chatterton, T. \& Longhurst, J. Evaluation of the First Round of the Local Air Quality Management Process: Report for Defra and the Devolved Administrations. Air Quality Consultants Ltd. \& AQM Resource Centre, Faculty of Applied Sciences, University of the West of England, Bristol, 2002.

[3] DEFRA and National Assembly for Wales. LAQM. PG (03) Policy Guidance. DEFRA: London, 2003.

[4] DEFRA, National Assembly for Wales, Scottish Executive, and Department of the Environment in Northern Ireland. LAQM. TG (03) Technical Guidance. DEFRA: London, 2003.

[5] Woodfield, N.K., Longhurst, J.W.S., Beattie, C.I. \& Laxen, D.P.H. The application of scientific uncertainty and error in the designated AQMAs of GB: Implications for further air quality assessments. In Urban Transport $I X$ (ed. by Sucharov, L.J. \& Brebbia, C.A.) Southampton, WIT Press. pp. 263-273, 2003.

[6] Woodfield, N.K., Longhurst, J.W.S, Beattie, C.I. \& Laxen, D.P.H. Emerging scientific decision making for designating air quality management areas in the UK. In Air Pollution IX. (ed. by Lantini, G. \& Brebbia, C.A.) Southampton. WIT Press. pp. 315-323, 2001.

[7] Longhurst, J. W. S., Beattie, C. I., Chatterton, T. J., Elsom, D. M, Leksmono, N. S. \& Woodfield, N. K. A critical evaluation of the local air quality management framework in Great Britain: Is it a transferable process? In Regional and Local Aspects of Air Quality Management (ed. by Elsom, D. M. \& Longhurst, J. W. S.). Southampton. WIT Press. pp. 51-81, 2004.

[8] AQEG. Nitrogen Dioxide in the United Kingdom. Defra, London, 2004.

[9] AQEG. Particulate Matter in the UK. Defra, London, 2005.

[10] Elsom, D.M. \& Crabbe, H. Practical issues involved in developing effective local air quality management in the United Kingdom. In Air Pollution III, Vol. 2. (Ed. By Power, H., Moussiopoulos, N. \& Brebbia, C.). CMP Publications, Southampton. pp. 483-492, 1995.

[11] Beattie, C.I. The Impact of the Implementation of the Environment Act 1995, Part IV (Air Quality) on the Air Quality Management Practices of Urban Local Authorities in England. Ph.D. Thesis, University of the West of England, Bristol. Faculty of Applied Sciences, 2003.

[12] Beattie, C. I., Elsom, D. M., Gibbs, D. C., Irwin, J. G., Jefferson, C. M., Ling, K., Longhurst, J. W. S., Pheby, D. F. H., Phil, M. A., Rowe, J., Simmons, A., Tubb, A. L. T., Whitwell, I., \& Woodfield, N. K. Best practice in English air quality management: principles illustrated by some examples if current practice. In Air Pollution VII (ed. by Brebbia, C. A., Jacobson, M. \& Power, H.). Southampton. WIT Press. pp. 199-211, 1999.

[13] Gibbs, D. C., Longhurst, J. W. S., \& Braithwaite, C. Moving Towards Sustainable Development? Integrating Economic Development and the 
194 Air Pollution XIV

Environment in Local Authorities. Journal of Environmental Planning and Management. 39. pp. 317-332, 1996.

[14] HM Government. Local Government Act 2000. London, The Stationery Office, 2000.

[15] Casella Stanger. Evaluation of Local Authority Air Quality Action Planning through Local Air Quality Management. Casella Stanger, London, 2004. 